\title{
A new missense mutation in the growth hormone-releasing hormone receptor gene in familial isolated GH deficiency
}

\author{
Mauri Carakushansky, Andrew J Whatmore ${ }^{1}$, Peter E Clayton ${ }^{1}$, Stephen M Shalet ${ }^{2}$, Helena K Gleeson ${ }^{2}$, \\ David A Price ${ }^{1}$, Michael A Levine and Roberto Salvatori \\ Divisions of Pediatric Endocrinology and Endocrinology and The Ilyssa Center for Molecular and Cellular Endocrinology, The Johns Hopkins University \\ School of Medicine, Baltimore, Maryland 21287, USA, ${ }^{1}$ Department of Pediatrics, Royal Manchester Children's Hospital, Manchester, UK and \\ ${ }^{2}$ Department of Medicine, Christie Hospital, Manchester, UK
}

(Correspondence should be addressed to Roberto Salvatori, Division of Endocrinology, Johns Hopkins University School of Medicine, 1830 East Monument Street \#333, Baltimore, Maryland 21287, USA; Email: salvator@jhmi.edu)

\begin{abstract}
Objective: Mutations in the GH-releasing hormone (GHRH) receptor (GHRHR) gene (GHRHR) cause autosomal recessive familial isolated GH deficiency (IGHD). We searched for GHRHR mutations in two siblings with IGHD type IB and a history of parental consanguinity.

Design: We analyzed peripheral genomic DNA of an index patient. After identifying a novel mutation in the GHRHR, we performed functional studies in order to confirm that the mutation causes receptor malfunction.

Methods: The entire GHRHR was analyzed in the index case by denaturing gradient gel electrophoresis. Abnormally migrating bands were isolated and sequenced. The mutated area was then sequenced in all family members whose DNA was available. The newly found mutation was inserted into a GHRHR cDNA. Wild-type and mutant cDNAs were expressed into CHO cells and the cyclic AMP (cAMP) response to GHRH was measured. In order to determine whether the mutant receptor was properly expressed on the cell membrane surface, $\mathrm{CHO}$ cells were transfected with wild-type or mutant GHRHR cDNA containing a FLAG epitope tag in the extracellular N-terminus.

Results: Both patients were homozygous for a new missense mutation in codon 176, corresponding to the second transmembrane domain of the receptor protein that replaces alanine with valine (A176V). The mother and three unaffected siblings were heterozygous for the mutation; DNA from the father was not available. Cells expressing the A176V receptor had a significantly reduced cAMP response to GHRH, despite appropriate expression on the cell surface.

Conclusions: We describe two siblings with IGHD due to a new mutation in the GHRHR that disrupts GHRH signaling and leads to GHRH resistance.
\end{abstract}

European Journal of Endocrinology 148 25-30

\section{Introduction}

Theoretically, familial isolated growth hormone (GH) deficiency (IGHD) can result from genetic defects that impair GH-releasing hormone (GHRH) synthesis, secretion, or action. IGHD can be inherited through several modes of transmission, and includes two autosomal recessive forms (IGHD IA and IB), as well as autosomal dominant (IGHD II) and X-linked (IGHD III) forms. The GHRH gene has been excluded as a candidate gene for IGHD by linkage analysis and direct sequencing (1). Conversely, unique mutations of the GHRH receptor (GHRHR) gene (GHRHR) have been described as the basis for IGHD IB in several kindreds (2-9). GHRHR mutations cause isolated GH deficiency because they impair responsiveness of pituitary somatotropes to GHRH. Patients with GHRHR mutation have marked dwarfism, and are phenotypically and biochemically indistinguishable from other forms of isolated $\mathrm{GH}$ deficiency. Here we describe phenotypical, hormonal and genetic findings in two siblings with IGHD IB and demonstrate that the disease phenotype is caused by a novel missense mutation in the GHRHR.

\section{Patients and methods}

\section{Patients}

Two male siblings born in Pakistan (patients 1 and 2) were referred to the Endocrine clinic at different times for evaluation of short stature at age 8.5 years (patient 1 ) and 8.4 years (patient 2). The two children were the products of full-term pregnancies from consanguineous parents (first cousins) and were born by spontaneous 
normal vaginal deliveries. Birth weights were 3.2 and $3.3 \mathrm{~kg}$ respectively. No history of neonatal hypoglycemia was present. They had no dysmorphic features, no microphallus, and except for short stature, their physical examination was normal. When first evaluated at the Royal Manchester Children's Hospital, their physical examinations were normal except for short stature: patient 1 was $104 \mathrm{~cm}$ (4.5 standard deviation below the 50th percentile of the normal growth curve), and patient 2 had a height of $108.5 \mathrm{~cm}(3.5$ standard deviation below the 50th percentile). They both had delayed bone age (calculated using the Greulich and Pyle Atlas): 6 years at a chronological age of 9 years for patient 1 and 7.5 years at a chronological age of 9 and $7 / 12$ years for patient 2 . They both had subnormal GH peak during sleep ( 3.6 and $1.5 \mathrm{mU} / \mathrm{l}$ respectively) and after stimulation with $0.5 \mathrm{~g} / \mathrm{kg}$ arginine (1.2 and $2 \mathrm{mU} / \mathrm{l}$ respectively), diagnosing $\mathrm{GH}$ deficiency (GHD). Patient 1 also underwent stimulation with $1 \mu \mathrm{g} / \mathrm{kg}$ GHRH, with no significant response (GH $<1 \mathrm{mU} / \mathrm{l}$ at all points). Magnetic resonance imaging (MRI) showed anterior pituitary hypoplasia in both patients. Pituitary function was otherwise normal. Both subjects had normal cortisol response to adrenocorticotropin, normal serum thyroxine, and a normal thyrotropin response to thyrotropin-releasing hormone. Both showed a good growth response to exogenous human recombinant GH therapy (0.025$0.03 \mathrm{mg} / \mathrm{kg} /$ day), underwent spontaneous puberty, and achieved predicted adult height based on parental stature (father is $168 \mathrm{~cm}$ and mother is $162 \mathrm{~cm}$ ): final stature of patient 1 was $169 \mathrm{~cm}$ while patient 2 achieved a final height of $171 \mathrm{~cm}$.

The subjects' parents gave informed written consent for the studies described below. The protocol was approved by the local ethics committee.

\section{Amplification of the GHRHR and mutation detection}

Genomic DNA was extracted from peripheral blood leucocytes by standard techniques. The 13 exons, the corresponding intron-exon boundaries and the proximal part (327 bp) of the GHRHR gene were individually amplified via PCR using primers and conditions described previously (5). One primer of each pair contained a $5^{\prime}$ GC-rich sequence 40 bases long, to increase the sensitivity of mutation detection via denaturing gradient gel electrophoresis (DGGE) (10-12).

PCR products were first analyzed by electrophoresis through $8 \%$ acrylamide gels and were then subjected to mutation analysis by DGGE. DGGE was performed at constant voltage $(80 \mathrm{~V})$ for $14-16 \mathrm{~h}$ at $60^{\circ} \mathrm{C}$ using a $7.5 \%$ acrylamide gel containing a linear gradient of $30-90 \%$ of the denaturants, urea and formamide. Each abnormally migrating band was isolated and sequenced directly using the Thermo-Sequenase Cycle Sequencing Kit (Amersham Pharmacia Biotech,
Arlington Heights, IL, USA). The prevalence of each newly discovered change in the coding region was determined by DGGE analysis of a commercial panel of genomic DNAs obtained from the DNA Polymorphism Discovery Resource that contains DNA samples from 44 anonymous unrelated normal individuals of diverse ethnicity (13). After the identification of the mutation in the index patients, all other available members of the family were genotyped via direct sequencing of the appropriate gene region.

\section{Transient expression of GHRHR and cAMP assay}

To determine whether the missense mutation altered receptor function, we used site-directed mutagenesis (14) to introduce the amino acid change into a wildtype GHRHR complementary DNA (cDNA) that contains the sequence encoding green fluorescent protein (GFP) at the C-terminus intracellular tail (PEGFP-N2 plasmid Clontech, Palo Alto, CA, USA). In agreement with data obtained with other similar G-proteincoupled receptors (15), in preliminary experiments we determined that this GFP-tagged cDNA has the same functional activity as the native receptor. Mutagenesis was confirmed by direct sequencing of the cDNA clones. The wild-type and mutant GHRHR cDNAs were transiently expressed in Chinese hamster ovary (CHO) cells. CHO cells at $70-80 \%$ confluence were transfected with $15 \mu \mathrm{g}$ plasmid DNA in T-75 flasks using lipofectamine (Life Technologies, Inc., Gaithersburg, MD, USA). Twenty-four hours after transfection, cells were harvested by trypsinization and seeded in 24-well dishes at $2 \times 10^{5}$ cells/well. The cells were cultured for an additional $24 \mathrm{~h}$ in preparation for cAMP experiments. Responsiveness of cells to GHRH was determined essentially as previously described (6). Briefly, culture medium was replaced with serum-free medium containing $0.5 \mathrm{mmol} / \mathrm{l}$ isobutylmethylxanthine and various concentrations of (His1, Nle27)GHRH-(1-32) (Peninsula Laboratories, Inc., Belmont, CA, USA) or forskolin $\left(10^{-5} \mathrm{~mol} / \mathrm{l}\right)$. After 15-min incubation at $37^{\circ} \mathrm{C}$, the reaction was stopped by addition of $100 \mu \mathrm{l} \mathrm{HCl}$ to a final concentration of $0.1 \mathrm{~mol} / \mathrm{l}$. Cells were subjected to a cycle of freeze-thawing, and total cellular cAMP in the acid extracts was measured by radioimmunoassay as previously described (16). Results were normalized to the cAMP response to forskolin and are expressed as picomoles cAMP per well. Data are the mean \pm s.E. of three independent experiments, each performed in triplicate. Results were analyzed by ANOVA using experimental means.

\section{Cellular expression of GHRH receptors}

CHO cells were cultured on glass coverslips to $70-80 \%$ confluence and transfected as described above with wild-type or mutant cDNAs encoding GFP-tagged 
GHRHRs. Cells were examined for fluorescence by confocal laser scanning microscopy (LSM 410, Carl Zeiss, Inc., Oberkochen, Germany) using a $\times 40$ objective. Samples were scanned for equivalent times with the same contrast and brightness settings.

In order to determine whether the mutant receptor was properly expressed on the cell membrane, CHO cells were transfected with wild-type or mutant GHRHR cDNAs containing a FLAG tag in the extracellular N-terminus (Invitrogen). Forty-eight hours after transfection, cells were fixed with methanol and $0.4 \%$ acetic acid, and exposed to anti-FLAG monoclonal M2 antibody $(2 \mu \mathrm{g} / \mathrm{ml})$ (Sigma). Fluorescein-labeled anti-mouse antibodies were used to detect the antigen, and cells were examined by confocal microscopy as described above.

\section{Results}

\section{Mutation identification}

Both patients were homozygous for a new missense mutation in codon 176 , a $\mathrm{C}$ to $\mathrm{T}$ transition that replaces alanine (GCG) with valine (GTG) in exon 6 (A176V), corresponding to the second transmembrane domain of the receptor protein (Fig. 1). The mother and three unaffected siblings were heterozygous for the same mutation, while DNA from the father was not available (Fig. 2). This change was not observed in any of the 88 normal chromosomes from the Polymorphism Discovery Resource, proving that this base change is not a common polymorphism.

\section{GHRH responsiveness}

As shown in Fig. 3, $\mathrm{CHO}$ cells that expressed the mutant GHRHR produced significantly lower cAMP responses to GHRH $\left(10^{-9}, 10^{-8}\right.$ and $\left.10^{-7} \mathrm{~mol} / \mathrm{l}\right)$ when compared with cells expressing the wild-type GHRHR, demonstrating that the amino acid change impaired the ability of the GHRH receptor to activate adenylyl cyclase.

\section{GHRH receptor expression}

Confocal microscopy showed that the GFP-tagged wildtype and $\mathrm{A} 176 \mathrm{~V}$ receptors were both expressed in the CHO cells (Fig. 4). FLAG-tagged wild-type and A176V receptors showed comparable surface distribution of fluorescence, indicating equivalent membrane receptor expression (Fig. 5). Cells that had been transfected with lipofectamine alone (no plasmid) showed no fluorescence.

\section{Discussion}

A significant percentage of cases of IGHD are familial (17), likely due to mutations in one of the genes involved in the synthesis or secretion of GH. The critical role that GHRH plays in regulating pituitary secretion of GH has been confirmed in mice (18) and humans (2) through the discovery of mutations in the GHRHR that inactivate receptor function, and cause severe GH deficiency. Approximately 25\% of children with IGHD do not increase their growth velocity after treatment with parenteral GHRH (19), which is consistent with impaired responsiveness of pituitary somatotropes to GHRH action. These observations indicate that mutations that inactivate the GHRHR may be a common cause of IGHD. Indeed, our recent demonstration of a relatively high frequency of compound heterozygosity for GHRHR mutations $(7,8,20)$ suggests that GHRHR mutations may be common in the population and may account for a subset of sporadic IGHD.

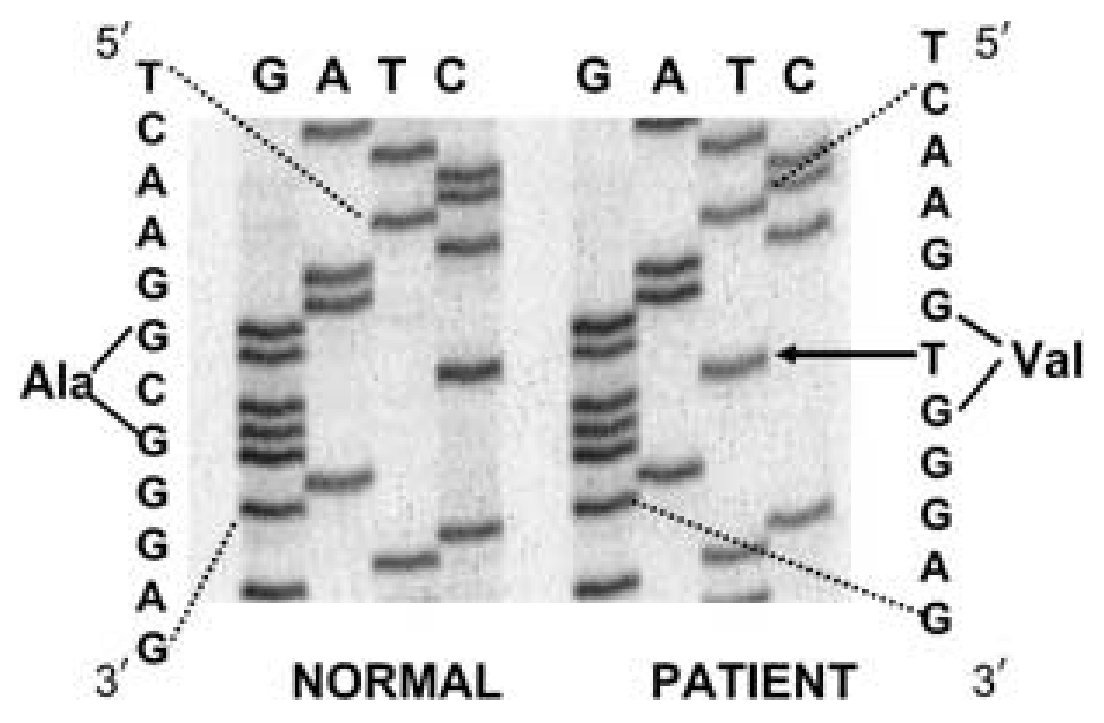

Figure 1 Sequence analysis of a portion of exon 6 of the GHRHR gene from genomic DNA of a normal subject and of patient 1. The homozygous $\mathrm{C} \rightarrow \mathrm{T}$ transition is indicated by the arrow. 


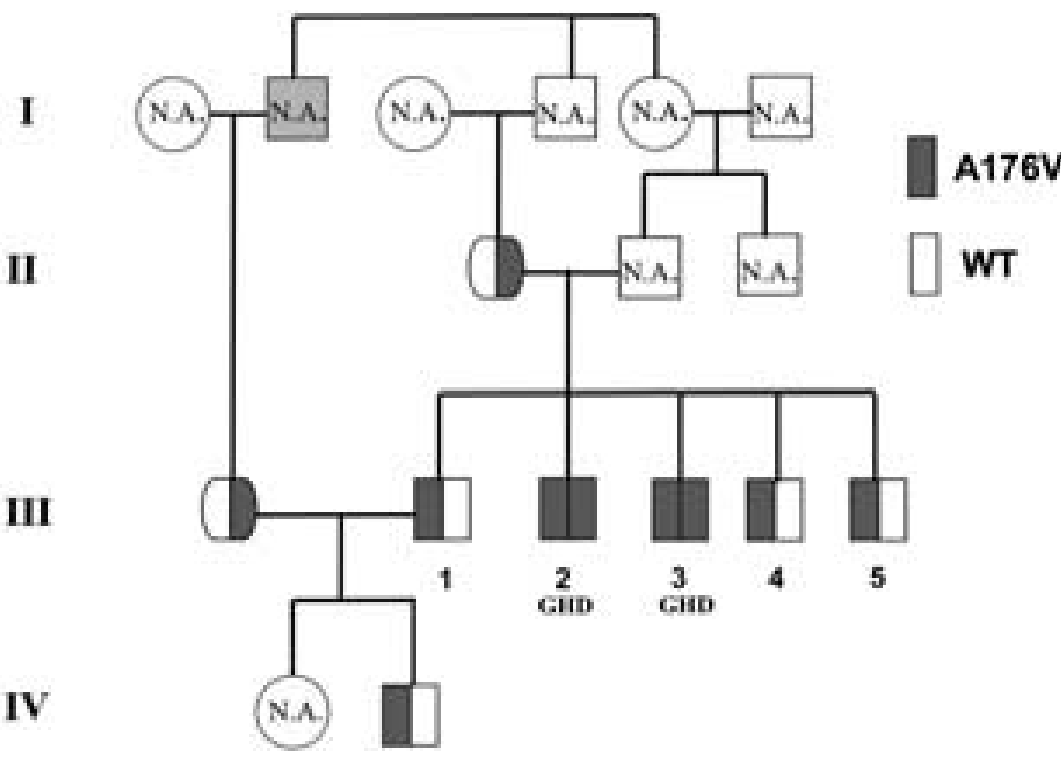

Figure 2 Pedigree of the family with the A176V mutation in the GHRHR. Squares indicate male family members; circles, female family members. Dark-gray symbols indicate subjects homozygous for the mutation; halfwhite symbols indicate genotype-confirmed heterozygotes. NA, DNA not available. The light-gray symbol in generation I indicates a possibly affected subject (by family history).
In this work, we screened the GHRHR in one IGHD family in which the presence of two affected siblings and parental consanguinity suggested a genetic cause of disease. The two affected siblings were homozygous for a $\mathrm{C}$ to $\mathrm{T}$ change in exon 6 that resulted in replacement of alanine 176 by valine. This substitution was not found in 88 chromosomes from unrelated normal subjects, indicating that this base change is unlikely to be a polymorphism. This alanine residue is conserved in all the GHRHR genes cloned to date, including ovine, bovine, porcine, rat and mouse, pointing to its structural importance for receptor function (21). Indeed, transient expression of GHRHR cDNA containing the mutation showed that mutant receptors failed to stimulate an increase in cAMP in response to GHRH, indicating that this mutation causes receptor malfunction and IGHD phenotype in the affected subjects.

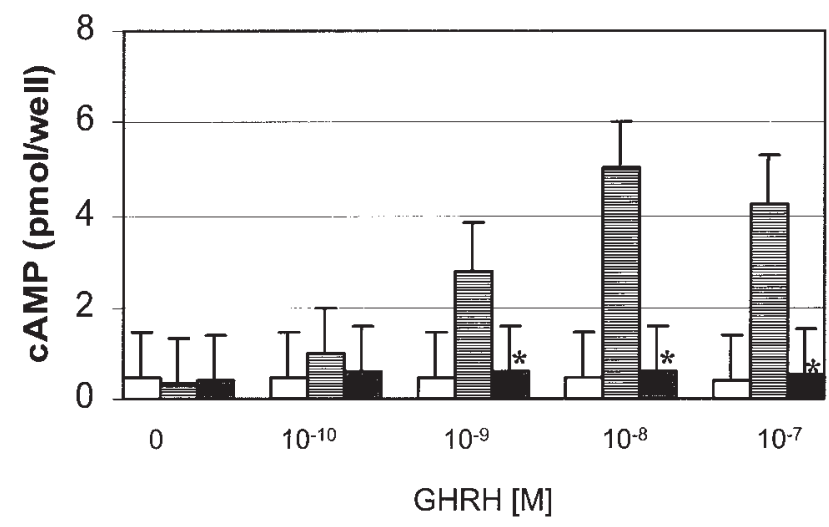

Figure 3 Basal and GHRH-stimulated intracellular cAMP levels in $\mathrm{CHO}$ cells transiently transfected with lipofectamine alone (open bars), or with wild-type (striped bars) or the mutant (A176V; solid bars) $G H R H R$ cDNA. * $P<0.001$ compared with wild-type.
Confocal microscopy studies using both GFP- and FLAG-tagged receptors showed that the mutant was expressed at comparable levels as the wild-type receptor, and that the mutation does not impair proper surface expression of the receptor.

The mechanism by which this and other GHRHR missense mutations cause receptor malfunction will require further investigation. Because the transmembrane domains of the GHRHR are important for GHRH binding specificity (22), it is possible that the A176V mutation may prevent binding of GHRH. Alternatively, it could interfere with coupling with G proteins. Further in vitro studies will answer this question and possibly give important information on which specific functions are associated with different regions of the receptor.

This is the sixth missense mutation in the GHRHR described to date $(6-8)$. The degree of growth retardation is similar to that observed in other patients. The presence of a possible phenotype-genotype correlation is difficult to ascertain due to the fact that patients from different kindreds are diagnosed, and therefore treated with exogenous $\mathrm{GH}$, at different ages, and often with different $\mathrm{GH}$ dosages. However, timely treatment with GH invariably causes good catch-up in growth and final stature that corresponds to the genetic target. One clinical finding invariably present in patients with bi-allelic GHRHR mutations is MRI evidence of pituitary hypoplasia. Although this is not a unique feature of GHRHR mutations, its absence excludes mutations in this gene.

In conclusion, we report two siblings in whom isolated GH deficiency is caused by a new GHRHR missense mutation that interferes with proper receptor function. GHRHR mutations are emerging as a common cause of familial IGHD IB. Factors that 
1

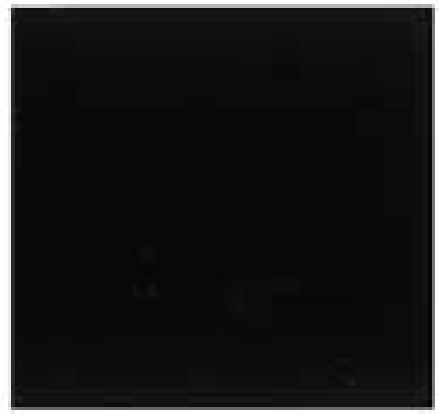

3

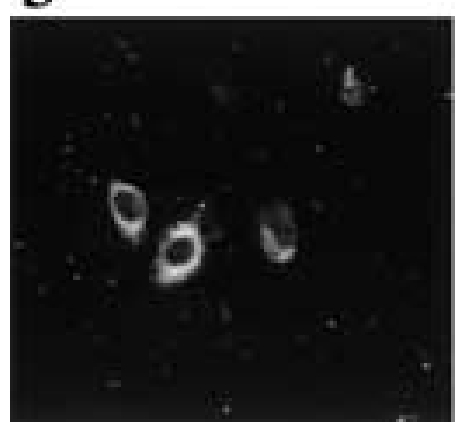

1

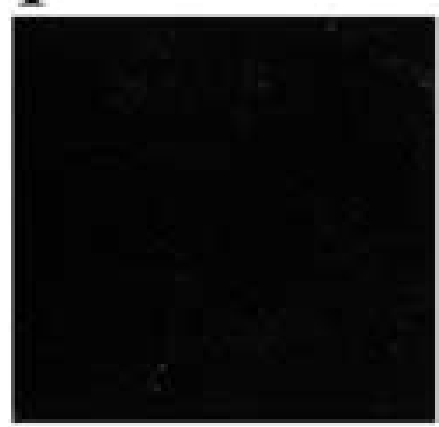

3

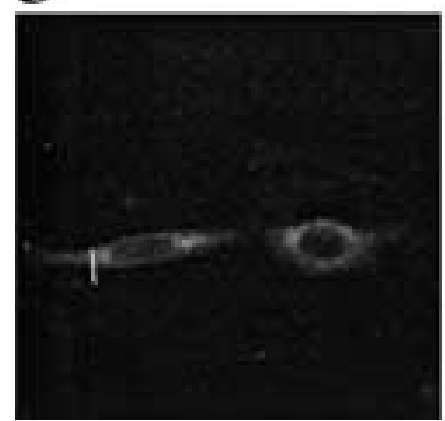

2

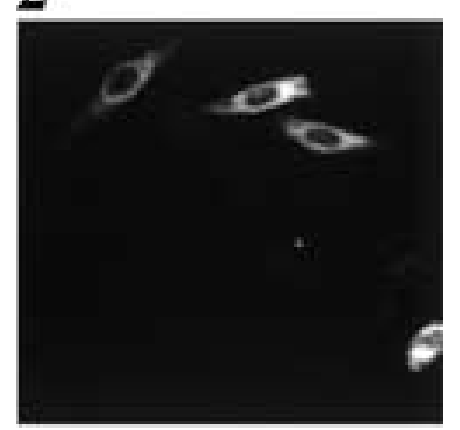

Figure 4 Confocal microscopy imaging of the C-terminally GFP-tagged GHRHR. $\mathrm{CHO}$ cells were transiently transfected with lipofectamine only (panel 1), or with wild-type (panel 2) or A176V mutant (panel 3) GHRHR cDNA.

2

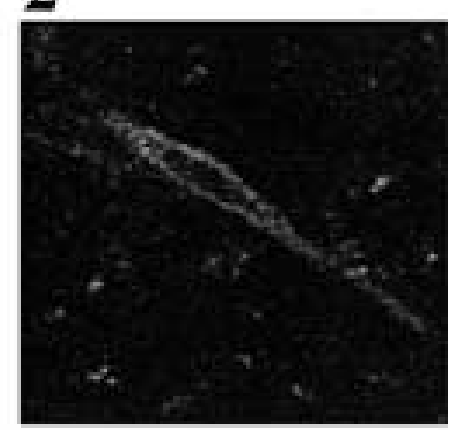

Figure 5 Surface expression of the

$\mathrm{N}$-terminally FLAG-tagged GHRHR. CHO cells were transfected with lipofectamine only (panel 1), or with wild-type (panel 2) or A176V mutant (panel 3) GHRHR cDNA, and not permeabilized, proving normal surface expression of the mutant receptor. 
might contribute to high prevalence include the longstanding custom of consanguineous unions in certain populations, high penetrance, and apparent lack of lethality (4).

\section{Acknowledgements}

We wish to thank the subjects who volunteered their time for the studies, and Dr Kelly Mayo (Northwestern University, Chicago, IL, USA) for generously providing the GHRHR cDNA constructs. This work was supported in part by NIH-NCRR GCRC-CAP award 3 M01 RR000052-38S1 (R S), and by a grant from the Genentech Center for Clinical Research and Education (R S). M C was supported, in part, by a grant from Pharmacia.

\section{References}

1 Perez Jurado LA, Phillips JA III \& Francke U. Exclusion of growth hormone-releasing hormone gene mutations in familial isolated growth hormone deficiency by linkage and single strand conformation analysis. Journal of Clinical Endocrinology and Metabolism $199478622-628$.

2 Baumann G \& Maheshwari H. The dwarfs of Sindh: severe growth hormone $(\mathrm{GH})$ deficiency caused by a mutation in the GH-releasing hormone receptor gene. Acta Paediatrica Supplement 1997423 33-38.

3 Netchine I, Talon P, Dastot F, Vitaux F, Goosens M \& Amselem S. Extensive phenotypic analysis of a family with growth hormone (GH) deficiency caused by a mutation in the GH-releasing hormone receptor gene. Journal of Clinical Endocrinology and Metabolism $1998 \mathbf{8 3} 432-436$

4 Maheshwari HG, Silverman BL, Dupuis J \& Baumann G. Phenotype and genetic analysis of a syndrome caused by an inactivating mutation in the growth hormone-releasing hormone receptor: dwarfism of Sindh. Journal of Clinical Endocrinology and Metabolism $1998834065-4074$.

5 Salvatori R, Hayashida CY, Aguilar-Oliveira MH, Phillips JA III, Souza AH, Gondo RG et al. Familial dwarfism due to a novel mutation in the growth hormone-releasing hormone receptor. Journal of Clinical Endocrinology and Metabolism $1999 \mathbf{8 4}$ 917-923.

6 Salvatori R, Fan X, Phillips JA III, Espigares-Martin R, Martin De Lara I, Freeman KL et al. Three new mutations in the gene for the growth hormone $(\mathrm{GH})$-releasing hormone receptor in familial isolated GH deficiency type IB. Journal of Clinical Endocrinology and Metabolism $200186273-279$.

7 Salvatori R, Fan X, Phillips JA III, Prince M \& Levine MA. Isolated growth hormone $(\mathrm{GH})$ deficiency due to compound heterozygosity for 2 new mutations in the GH-releasing hormone receptor gene. Clinical Endocrinology 200154 681-688.

8 Salvatori R, Fan X, Mullis PE, Haile A \& Levine MA. Decreased expression of the GHRH receptor gene due to a mutation in a Pit-1 binding site. Molecular Endocrinology 200216 450-458.
9 Salvatori R, Aguiar-Oliveira MH, Monte LVB, Hedges L, Santos NL, Pereira RMC \& Phillips JA III. Detection of a recurring mutation in the human GH-releasing hormone receptor gene. Clinical Endocrinology $2002 \mathbf{5 7} 77-80$.

10 Sheffield VC, Cox DR, Lerman LS \& Myers RM. Attachment of a 40-base-pair $\mathrm{G}+\mathrm{C}$-rich sequence (G-C clamp) to genomic DNA fragments by the polymerase chain reaction results in improved detection of single-base changes. PNAS $1989 \mathbf{8 6} 232-236$.

11 Fodde R \& Losekoot M. Mutation detection by denaturing gradient gel electrophoresis (DGGE). Human Mutations 19943 83-94.

12 Miller KM, Ming TJ, Schulze AD \& Withler RE. Denaturing gradient gel electophoresis (DGGE): a rapid and sensitive technique to screen nucleotide sequence variation in populations. Biotechniques 199927 1016-1018.

13 Collins FS, Brooks LD \& Chakravarti A. A DNA polymorphism discovery resource for research on human genetic variation. Genome Research 19988 1229-1231.

14 Kunkel TA. Rapid and efficient site-specific mutagenesis without phenotypic selection. PNAS $198582488-492$.

15 Tarasova NI, Stauber RD \& Wank SA. Characterization of receptor trafficking with green fluorescent protein. In Regulation of $G$ Protein-Coupled Receptor Function and Expression, ch. 12, pp 253-272. Ed JL Benovic. New York: John Wiley \& Sons, 2000.

16 Levine MA, Eil C, Downs RW \& Spiegel AM. Deficient guanine nucleotide regulatory unit activity in cultured fibroblast membranes from patients with pseudohypoparathyroidism type I. A cause of impaired synthesis of $3^{\prime}, 5^{\prime}$-cyclic AMP by intact and broken cells. Journal of Clinical Investigation 198372 316-324.

17 Cogan JD \& Phillips JA III. Growth disorders caused by genetic defects in the growth hormone pathway GH deficiency. In Advances in Pediatrics, pp 337-361. Eds LA Barness, G Morron III, AM Rudolph, DC De Vivo, MM Kaback \& WW Tunnessen Jr. Mosby: St. Louis, 1998.

18 Lin SC, Lin CR, Gukovsli I, Lusis AJ, Sawchenko PE \& Rosenfeld MG. Molecular basis of the little mouse phenotype and implications for cell type-specific growth. Nature $1993 \mathbf{3 6 4} 208-213$.

19 Thorner MO, Rochiccioli P, Colle P, Lanes R, Grunt J, Galazka A et al. Once daily subcutaneous growth hormone-releasing hormone therapy accelerates growth in growth hormone-deficient children during the first year of therapy. Journal of Clinical Endocrinology and Metabolism 199681 1189-1196.

20 Salvatori R, Fan X, Veldhuis J \& Couch R. Serum GH response to pharmacological stimuli and physical exercise in two siblings with two new inactivating mutations in the GH-releasing hormone receptor gene. European Journal of Endocrinology 2002147 591-596.

21 Horikawa R, Gaylinn B, Lyons CE \& Thorner MO. Molecular cloning of ovine and bovine growth hormone-releasing hormone receptors: the ovine receptor is C-terminally truncated. Endocrinology 2001142 2660-2668.

22 DeAlmeida VI \& Mayo KE. Identification of binding domains of the growth hormone-releasing hormone receptor by analysis of mutant and chimeric receptor proteins. Molecular Endocrinology $199812750-765$.

Received 26 August 2002

Accepted 8 October 2002 